\section{Making change through local food production: Calculating the economic impact of your local food project}

\author{
D ave Shideler a* \\ Oklahoma State University \\ Philip Watson ${ }^{b}$ \\ University of Idaho
}

Submitted April 11, 2018 / Revised August 20, and September 26, and October 3, 2018 /

Accepted O ctober 3, 2018 / Published online January 23, 2019

Citation: Shideler, D ., \& Watson, P. (2019). Making change through local food production:

Calculating the economic impact of your local food project. Journal of A griculture, F ood Systems,

and Community D evelopment, 8(Suppl. 3), 165-177. https:/ / doi.org/ 10.5304/ jafscd.2019.08C.011

Copyright @ 2019 by the Authors. Published by the Lyson Center for Civic Agriculture and Food Systems. Open access under CC BY license.

\begin{abstract}
Given the growing interest in local food systems and the complexity of modeling the economic impacts of such systems, the Local Food Impact Calculator (LFIC) was created to provide a simple but methodologically sound tool to assist practitioners. In this paper, we cite four examples, along with discussion of each, to illustrate both the use and application of the calculator, as well as to provide additional insights into using the calculator. Readers will learn that economic impact analysis provides information about industrial linkages in the local economy, and how to understand the implied multiplier's value from the LFIC in the context of their local economy. When used

a * Corresponding author: Dave Shideler, D epartment of Agricultural Economics, O klahoma State University; $323 \mathrm{Ag}$ Hall; Stillwater, OK 74078 USA; +1-405-744-6170; Dave.shideler@okstate.edu

b Philip Watson, Agricultural Economics and Rural Sociology, University of Idaho; 875 Perimeter D rive MS 2334; Moscow, ID 83844-2334 USA; pwatson@uidaho.edu
\end{abstract}

carefully, the LFIC can be a useful tool for use in community conversations around local foods.

\section{Keywords}

Local Food, Input-O utput Model, Economic Impacts, USD A Local Food Systems Toolkit

\section{Introduction}

With many people believing that more localized activities can improve environmental outcomes, enhance public health, and increase a community's resiliency to external and natural risks, there has been growing public interest in regionally focused food systems (Martinez et al., 2010; Stickel \& D eller, 2014; Thilmany McFadden \& Low, 2012). These issues include improving environmental outcomes, providing market access and sustainable financial models for small and mid-sized farms,

\section{Funding Disclosure}

Funding was provided by U.S. D epartment of Agriculture National Institute of Food and Agriculture Award Number 2014-68006-21871. 
enhancing public health, increasing a community's resiliency to external and natural risks, and supporting community-based economic development strategies (Martinez et al., 2010; Stickel \& D eller, 2014; Thilmany McFadden and Low, 2012). In recent years, the local foods movement was ranked as a "top story" by several food industry media outlets, including the Packer, ${ }^{1}$ a fresh produce news outlet, and the National Restaurant Association's annual What's Hot list. ${ }^{2}$ Farmers markets, along with community supported agriculture operations (CSA), roadside stands, and direct-to-restaurant sales, are all growing market niches, where the number of farms engaged in direct-to-consumer marketing grew by $17 \%$ from 2002 to 2007 , and grew an additional 6\% from 2007 to 2012, as measured in U.S. Census of Agriculture data every five years (U.S. D epartment of Agriculture, 2009; 2014). Subsequently, there is an increasing array of policies and programs targeted to support the development of food system innovations. Y et critics note that such programs are being put forth without adequate evaluation of how local foods will affect market performance and the welfare of key stakeholders, especially the small and midsize farms that many local food buyers may believe they are supporting with their dollars (O nozaka \& Thilmany McFadden, 2011).

Q uantifying the economic impacts and contributions of local and regional food systems and events within these systems has become more common as both public and private entities attempt to justify a commonly held belief that more localized food systems lead to positive economic gains to the smaller-scale producers and the communities in which they operate. Several challenges remain relatively untouched in regard to local food system research literature and outreach programming. For example, there is little consensus about the definition of local and regional markets (Martinez et al., 2010; Watson, Cooke, Kay, Alward, \& Morales, 2017). Moreover, the Agriculture of the Middle research group ${ }^{3}$ suggests that evaluating the economic impacts of more coordinated value added activities in local economies will likely vary depending on the ownership, governance, and operational model of the value added enterprise as well as spillovers to other sectors of the economy. Such complexity in defining local and regional markets, and diversity among initiatives, calls for careful development and execution of input-output-based economic contribution analyses. Previous studies on innovations and events within local and regional food systems have taken a more simplified view of the supply chain. Such a view warrants a more careful focus on how, for example, small and medium-sized farmers may produce differently than large-scale commodity producers, as the field moves forward.

Some studies have used input-output models (I-O) and investigated the economic impacts of a more localized food system on market players. However, most of these studies were based on surveys of markets and consumers and used data from sales and financial reports (Brown \& Miller, 2008; D arby, Batte, Ernst, \& Roe, 2008; Myers, 2006). More recently, studies have evaluated the impact of state-based food promotions using more theoretically based economic models (e.g., Carpio \& Isengildina-Massa, 2010). But with a focus primarily on consumers' responses to promotions of local or state-based labels, such I-O studies may neglect supply-side implications related to the restructuring of supply chains. Others have begun filling this gap using a systemwide economic approach, which examines how consumers' response and the restructuring of the supply chain to smaller-scale production affect the welfare of consumers, producers, and agents along the supply chain, who could be the producers themselves $(\mathrm{Hu}$, 2012). It must be noted, however, that each I-O study uses different assumptions, sometimes without the context of actual marketing and business models employed by producers or producer collaboratives, making their results difficult to compare and contextualize.

Increasing complexity of I-O analysis led to the development of the USD A Agricultural

\footnotetext{
1 https:/ / www.thepacker.com/

2 https:/ / www.restaurant.org/ News-Research/ Research/ What-s-Hot

3 http:// www.agofthemiddle.org/
} 
Marketing Service's "The Economics of Local Food Systems: A Toolkit to G uide Community Discussions, Assessments and Choices" (Thilmany McFadden et al., 2016), which guides organizations in regard to the type of data to collect, appropriate methods of data collection, and steps for analyzing the collected data. The AMS Toolkit helps address the issue of assumptions and standardization of methods, leading to comparable I-O results. However, Angelo, Jablonski, and Thilmany (2016) concluded that most organizations involved in local food system development do not have the expertise or data available to reasonably conduct an economic impact analysis, finding that only half of case studies on local food participants reported revenue, and less than ten percent reported detailed expenditure data on costs of goods sold or labor. Additionally, one must invest in the purchase of the IMPLAN data (currently US\$800 per county) to fully utilize the AMS Toolkit. For a cooperative food hub that serves four counties, US\$3,200 for a single report may be cost-prohibitive.

Therefore, even with refined methodologies in the academic literature and implementation guides to instruct users on developing their impact models, obstacles remain to building reasonable I0 estimates of local food system impacts. The Local Food Impact Calculator (LFIC), a freely available and simple-to-use online tool to estimate the economic impact of a food project, can provide methodologically consistent and comparable results across food projects but at a significantly reduced cost compared with IMPLAN. In this paper, we present four examples of the LFIC, discussing the results and value of its output, and then conclude by discussing the limitations of the calculator.

\section{Literature Review}

As noted in the introduction, the economic literature aimed at quantifying the impacts and contributions of local and regional food systems as well as the events of local food systems with inputoutput models has evolved quickly in recent years, but in a pattern that suggests there is no clear "standardized" approach or trajectory that the field is adopting as a best practice. This literature began with a simple approach, assuming that an increase in business conducted locally represents new spending in the local economy. Next, a layer of complexity was added when it began including spillover effects: the extra money spent in a local community, say at a farmers market, has both direct impacts for the farmers but also for the businesses surrounding the market that might see gains from increased foot traffic and patronage. Researchers also began to carefully delineate exactly how much of the spending in local and regional food systems could truly be considered an impact rather than a more locally derived contribution; that is to say, how much of the spending on local foods is a reallocation of existing income versus import substitution (an economic development method that decreases the importation of items by substituting locally produced goods). Incorporating these countervailing effects into the analysis could act to partially mitigate positive gains in a food system. The most recent innovations in the literature have utilized more complex modeling techniques, such as equilibrium displacement models (EDM) and hybrid models, where the latter combines multiple modeling techniques or modifies existing sectors in commercially available software such as IMPLAN. This evolution of the literature is discussed below.

The most straightforward and simple approach to estimating economic impacts and contributions is to assume that when more money is spent at a local business, spending leads to an economic gain for the community. Brown and Miller (2008) conducted a review of the literature on the impacts of farmers markets and community supported agriculture (CSA), an update of a previous study conducted by Brown (2002). This article highlights many of the studies in which impacts were estimated by taking the money spent at a farmers market, plugging these estimates into the economic impact modeling software IMPLAN, and providing an estimate of the total economic impact of a farmers market, including both direct and indirect impacts to the local community (examples of studies that use this methodology include Henneberry, Whitacre, and Agustini, 2009; Myers, 2006; and Otto and Varner, 2005). An implicit assumption made in these studies is that the spending at the farmers market represents new money introduced into the local economy, which is rarely 
the case. Another assumption made is that local food producers utilize the same production techniques as commodity-scale producers. Thus, some would argue these studies could both underestimate and overestimate impacts due to the simplicity of assumptions. For instance, the assumption that purchases at the farmers market count as "new spending" in the economy fails to acknowledge the competition that likely exists between the market and the local grocery store. In this case, disregarding this competition leads to an overestimation of the impact. Alternatively, only focusing on farmers market sales ignores the unique production practices associated with local food systems (e.g., they tend to be more labor-intensive) and could underestimate the impact. Thus, more thoughtful and complex scenarios were constructed to more accurately account for the net impacts associated with changes in local food systems.

The next evolution in this field of research added complexity by including spillover effects. Spillover effects of economic activity- the dollars spent within a region that are attributable to a given industry, event, or policy (Watson et al., 2017) - can be defined as either the positive or negative impact of a certain activity to members of localities and economic sectors that are not direct beneficiaries. There are two main types of spillover effects. The first type is when the economic activity of the industry or event in question drives more (or less) money to surrounding businesses, since it serves as a catalyst for patronage. For example, consumers who attend the farmers market located in a downtown shopping district may also frequent shops near the farmers market. The second type is related to the supply chain and occurs when a business or industry gains enough critical mass to induce input suppliers, or output users, to move to the region. With more of the economic activity staying local (or being able to be sourced locally if suppliers move in), the economic impacts or contributions are higher as less money is "leaked" out of the economy, known as "import substitution" in the academic literature.

Most of the research on the economic impacts and contributions of localized food systems has focused on the first type of spillover effects. Lev,
Brewer, and Stephenson (2003) and O berholtzer and Grow (2003) found that people who visit farmers markets end up spending additional money in downtown areas, bringing additional revenue to businesses in neighboring communities. Watson, Thilmany, and K ress (2006) found that the economic contribution of the Colorado wine industry included tourism impacts from tasting rooms and wine festivals, and that these tourism impacts were actually larger than those from the sale of wine. This difference was due to both the fledgling nature of the wine industry and the amenity-rich tourism regions where the wine industry was forming. Hughes, Brown, Miller, and McConnell (2008) studied the economic impact of farmers markets in West Virginia, using a combination of survey data and IMPLAN, to also model spillover effects by including tourism impacts from the market. O'Hara and Shideler (2018) found that increasing direct-to-consumer agricultural sales led to increased restaurant sales in metropolitan counties across four states. The second type of spillover effects, those related to supply chain innovations, have been explored in the context of value chain analysis (D ay-Farnsworth, McCown, Miller, \& Pfeiffer, 2009; Diamond \& Barham, 2011; Matson, Sullins, \& Cook, 2013; Stevenson et al., 2011), but have yet to be studied in the economic impact literature.

Including spillover effects helps mitigate the underestimation of effects, while the next innovation, accounting for countervailing effects, mitigates the potential for overestimation. Purchasing local food could simply be shifting purchases from one business to another; it may not fundamentally change the amount of money being spent in an economy (e.g., one consumer shifts her purchases of tomatoes from the local grocery to the farmers market). Similarly, when studying the impacts of increased local vegetable production, acres must shift from one land use to another, since new acreage is rarely created. The studies that take into account the countervailing effects and report net, rather than gross, impacts provide the best guidance for future research because of their consistency with economic theory. Examples of these innovations include Swenson (2006); Swenson (2010); Conner, Knudson, Hamm, and Peterson 
(2008); and Hughes et al. (2008).

Swenson (2006 and 2010) use IMPLAN to measure the potential net economic impacts that could accrue to the state of Iowa if it were to increase selected fruit and vegetable production for all marketing channels. The studies suppose that if the farmland used to grow the fruits and vegetables were taken out of corn and soybean production, there would be countervailing supply-side effects from the lost corn and soybean production. Conner et al. (2008) use IMPLAN to study the economic impact in Michigan if residents were to increase fruit and vegetable consumption to the recommended levels by consuming Michigangrown produce. Like Swenson, they assumed production shifted from existing crop acreage (albeit shifting to higher-value crops). Rossi, Johnson, and Hendrickson (2017) report net impacts of shifting production out of US\$1 million worth of commodities and into US\$1 million of produce for three regions in Missouri and Nebraska.

In another example, unlike much of the previous research on farmers markets, Hughes et al. (2008) incorporated countervailing demand effects, reporting the net impact of farmers markets rather than the gross impact. The net impact assumed that money spent at the farmers markets was money not being spent at grocery stores. Therefore, all economic gains were due to the larger multipliers for the farming sector compared to the retail grocery sector. (Multipliers are simply the ratio of the total output impact from the analysis to the initial event, or direct impact, being studied. They are a common way of describing the magnitude of change in the economy from an initial local change, like the emergence of local food sales.) Similarly, G unter and Thilmany (2012) analyzed the economic impact of farm-to-school procurement using a similar approach, attempting to more accurately model local food procurement for a farm-toschool program by assuming demand simply shifts from wholesalers to producers in the region. The same positive shock occurring in the local farming sectors, because of retained ownership and higher returns to the producer, is made negative in the context of the wholesale sector.

Recognizing the complexity of local food systems and their interactions with the economy prompted more complex modeling approaches that allow for more dynamic changes to the economy, such as hybrid models that include modifications to the existing sectors in IMPLAN, and equilibrium displacement models. Because IMPLAN estimates are based on regional and sometimes national averages - and most likely represent past economic linkages- modification of IMPLAN sectors is necessary to accurately capture economic impacts and contributions of local and regional food systems due to unique ownership and operational models. Hughes et al. (2008) modified the farming sectors in IMPLAN to more accurately represent the noncorporate structure of small West Vinginia farmers by reducing payments to the property income category and increasing payments to proprietors' income. Gunter and Thilmany (2012) utilized survey data to customize farming sectors to accurately reflect the much smaller and more diversified local food producer who provides most of the marketing and distribution services themselves. Schmit, Jablonski, and Mansury (2016) used survey data on labor time allocations collected from small-scale producers in New Y ork to generate a customized, small-scale, direct agriculture sector for use in IMPLAN analysis.

An alternative to customizing the production data in IMPLAN is to exploit the existing data in IMPLAN's social account matrix, the table of transactions between industries and final consumers of output. The methodology, detailed by Miller, Mann, Barry, Kalchik, Pirog, and Hamm (2015) and Watson et al. (2017), does not require additional data or even segmentation of the local food sector from other agricultural production, although it does require access to IMPLAN or similar social accounting data (e.g., U.S. Bureau of Economic Analysis' RIMS II data). Not having to collect data from producers is appealing, though the consequence is that local foods become defined as any food product produced and consumed within the study region irrespective of the marketing channels used to get the food to its final consumer. (For example, all Michigan apples, whether sold to a Michigan resident at Walmart or the farmers market, would be considered local.) Using this general methodology, Watson et al. (2017) modeled local food systems as an import-substitution 
phenomenon, where it is assumed that if a local food system were not present in a region, then food would need to be imported and some of the production linkages within the region would be broken. In this way, the local food system potentially both creates more local economic activity by substituting for imported production, and simultaneously increases the local multipliers because more inputs are able to be purchased locally.

While the academic literature does provide important guidance for generating theoretically consistent and empirically sound analyses, the lack of consistency and burden of knowledge and resources required to implement them is significant. Additionally, these burdens make these studies inaccessible to either the local food participant and/ or government official seeking validation of a project. The Local Food Impact Calculator was developed as a tool to balance the need for a legitimate and standardized method for estimating economic impacts of local food projects, while managing the costs to those seeking to utilize this form of evaluation. (While the Local Food Impact Calculator is free to use, it still requires time to calculate the appropriate value of the project's impact.)

\section{Local Food Impact Calculator}

Building on the existing literature, but with a nod to creating a tool that is simple to use, easily accessible, and methodologically sound, the Local Food Impact Calculator ${ }^{4}$ (LFIC) seeks to provide a reasonable alternative to economic impact analysis for non-economists. Following the academic literature, the multipliers used to estimate project impacts were generated using a "local food" production function, computed from the average expenditures reported by farms with positive direct-to-consumer sales in the 2014 Agricultural Resource Management Survey (ARMS), Phase III. (The steps to generate a production function from survey data are detailed in Schmit and Jablonski, 2017, and in Module 7 of Thilmany McFadden et al., 2016, so they are not detailed here.) Since the social accounting data used to generate multipliers varies by region, the multipliers were generated for geographies representative of the types of region contained in the calculator. These regions include three counties defined by population (rural- fewer than 75,000; suburban-75,000 to 200,000; and urban- over 200,000), a multicounty region (a region with a population between 500,000 to $1,000,0000$ containing an urban core and surrounding counties), two state-level regions (California, given its unique diversity and productivity in agriculture, is one state; all others are modeled separately), and a multistate region. The regions were constructed using regional purchase coefficients (the proportion of local demand that is supplied locally; RPCs) averaged across five randomly selected regions that fit the definitions used by the LFIC. In the case of the county-level models within the LFIC, county RPCs were averaged to create the respective LFIC county level regions. In the case of the multicounty region, the RPCs from counties that made up five randomly selected medium-sized metropolitan statistical areas (MSAs with a total population of 500,000 to 1 million) were averaged..$^{5}$ In this way, idiosyncratic differences that were specific to any one region were averaged out to construct the LFIC regions. The LFIC regions, therefore, represent "typical" or "average" regions for their respective categories. LFIC users are asked to select the region that best reflects the scope of their project. For example, if the local food project is focused on a particular county, users select the county type most similar to the location of the project. However, if the project includes multiple counties with an urban core, then the user is instructed to select the multicounty region. In this sense, the LFIC follows recommended practices from the literature while

4 Available online at https:/ / localfoodeconomics.com/ benchmarks/ impact-valuation/

5 The counties that were randomly selected for small counties were Cortland County, NY; Atascosa County, TX; Franklin County, KY; D earborn County, IN; and Columbia County, OR. The counties randomly selected for the medium-sized counties were Dubuque County, IA; Ashtabula County, OH; Hanover County, VA; D eKalb County, IL; and Carroll County, GA. The counties selected for the large counties were Cook County, IL; Maricopa County, AZ; Harris County, TX; King County, WA; and Prince George's County, MD. The medium-sized MSAs randomly selected for the multicounty region were Twin Falls, ID; Lafayette, LA; Fort Wayne, IN; Trenton, NJ; and Fort Smith, AR. 
maintaining some flexibility to accommodate a variety of sizes of projects.

For simplicity, the user is asked to enter the total sales or value of output generated by the local food project. These are specific values to economists that represent the gross level of economic activity generated directly by the food project. Total sales, also known as value of output, is equal to the sum of the value of all products sold at their retail price (i.e., the price at which they were sold to the final consumer) for the entire season or year (if the organization produces year-round). Alternatively, value of output is the total revenue received by the farmer, vendor, or organization. For example, a farmers market vendor would add up total sales from each market day, across the market season, to calculate value of output for the LFIC. Calculating the net level of economic activity - the value added, as would be suggested by the academic literature discussed above- would require the user to subtract all non-labor, purchased inputs from total sales. As mentioned previously, this data is not likely to be accessible to LFIC users, given that less than $10 \%$ of case studies on local food efforts contained expenditure data (Angelo et al., 2016). Nevertheless, the LFIC provides a consistent scenario from which results can be compared given the fixed production, geographic choices, and consistency of data inputted into the calculator.

The LFIC is not meant to replace a well-constructed economic impact analysis conducted by a qualified analyst. Instead, the calculator was created as an educational and informational tool; that is, it is meant to illustrate to the user the level of connectedness one's local food project may have to the region's economy. In this way, this tool can educate the community about the linkages which may or may not exist in a given community. Inputoutput analysis generates very precise estimates of economic impact, but, because of issues surrounding the underlying data and methodologies (many of which are described above in the literature review), most academics recognize that the estimated multiplier approximates the true impact. Therefore, the precise number is less important than its relative magnitude (e.g., "closer to" 1 or "closer to or greater than" 2). Furthermore, because the implicit multipliers and economic impact results from the calculator are for an average region, they do not reflect the specific characteristics of the project's region. Users thus are encouraged to nuance the values of the calculator in order to reflect actual characteristics of the project's region. Four examples that compare the calculator-estimated values with those reported in the academic literature illustrate how one might adjust calculator estimates based on local conditions. Such adjustments to the LFIC will be ordinal (i.e., greater than or less than the LFIC estimate) and not cardinal (i.e., increase or decrease by a specific amount), primarily because the implied multipliers are not meant to be interpreted as precise numbers. Adjustments can be made by comparing the actual economy in which the food project occurs to the LFIC regions in the following ways:

- Is the actual economy closer to the upper or lower population limit for the region selected? If the local economy is closer to the upper limit, the true multiplier is likely to be higher than the LFIC estimate, as a large population is expected to support a larger, more diverse economy. Conversely, if the local economy is closer to the lower limit, then the true multiplier is likely to be less than the LFIC estimate.

- Is the actual economy within, or adjacent to, a metropolitan statistical area? If so, the local economy serves a region larger than just the local population, so one would expect the true multiplier estimate to be higher than that generated by the LFIC.

- Is the actual economy known for agricultural production-i.e., is agriculture a visibly large part of the local economy? If so, the local economy probably possesses more businesses that provide inputs to agriculture than the "average" region in the LFIC. Therefore, one would expect the local multiplier to be higher than the LFIC estimate.

- Across the regional purchase coefficients for all expenditures in the LFIC, the industry-specific RPCs were remarkably 
consistent across regions within the respective categories except for fuel purchases. The amount of fuel purchased that was sourced locally was very dependent on whether a petroleum refinery was located within the region. Therefore, if a local refinery is present, the LFIC will underestimate the true multiplier of the project, as it will not account for local fuel purchases.

\section{Example 1: Kane County, Illinois (An Urban County)}

Kane County, Illinois, is located due west of the city of Chicago and is part of the Chicago-

Naperville-Elgin, Illinois-Indiana-Wisconsin MSA. The 2010 census counted 515,269 persons living in the county. Swenson (2013) conducted an analysis of two scenarios to depict the economic contribution from local production of 24 fruits and vegetables that could be grown in the region. Scenario 1 depicted the case when all produce was sold only within Kane County; this is an unrealistic assumption, but it provides a calculation of the potential local demand and supply of these fruits and vegetables. Scenario 2 allows for the produce to be sold throughout the metropolitan area (i.e., outside of Kane County), meaning that producers could face additional competition for their produce. This example will focus only on the second scenario.

Swenson estimates that the 24 fruits and vegetables produced in the county would generate US $\$ 9.45$ million in farm sales, require the use of 2,496 (1,010 hectares) of the county's 148,700 acres $(60,177 \mathrm{ha})$ of harvested field crops, and serve 445,328 individuals. The analysis suggests that the total contribution of this local production to the county economy is US $\$ 14.85$ million and 103 annualized jobs, adjusted for seasonal employment. This implies a multiplier of 1.57. The multiplier, computed as the ratio of total impact to direct impact, describes how an additional unit of expenditure would affect the local economy. In this instance, US\$1 spent on fruit and vegetable production would lead to an overall impact on the local economy of US $\$ 1.57$ (which includes the initial impact plus the supply-chain purchases and labor income effects). When this scenario is estimated using the LFIC, the total impact is measured to be US\$13.26 million, which implies a 1.40 multiplier. It is not surprising that the LFIC underestimates the impact of local food production in Kane County, given that the county's population is high and it is located within the Chicago metro area. Furthermore, a business search reveals that Kane County is home to numerous bakeries that serve the Chicago metro area, as well as an oil refinery. Bakery staff indicate that a large demand for agricultural products exist in the area. All these factors suggest that the local production stimulated by the increased fruit and vegetable production of Swenson's scenario should generate a larger impact than the average economy in LFIC.

\section{Example 2: Old Trails Region, Missouni (A 5-county Region Located Between Kansas City and Columbia, MO)}

As reported in Rossi et al. (2017), the agricultural commodities of this region included row crops, commodity cattle production, and commercial orchards; they estimate that $5 \%$ of farms in the region engage in direct-to-consumer agriculture. These authors also note that in recent years the region has become a destination for travelers seeking amenity-driven experiences such as orchards, wineries, and bed and breakfasts. Using data collected from a survey of producers selling locally marketed agricultural products, Rossi et al. generate a set of regional purchase coefficients for these farmers and ranchers that they then use to estimate the indirect and total impacts of production across a basket of goods totaling US\$1 million in value. These impacts were compared with the same basket of goods produced using the default regional purchase coefficients in IMPLAN. Interestingly, the authors found that local food total sales had a higher impact on the Old Trails economy than conventional agriculture, but employment impacts from local food sales were lower. The total effect of the US\$1 million local production scenario in this region, as presented in the article, is US\$1.77 million, or a multiplier of 1.77. The LFIC estimates the total impact to be US\$1.39 million, which underestimates the economic impacts of the local food system in the region by US $\$ 380,000$ compared with the Rossi et al. (2017) results. O ne explanation for the 
difference in values could be the presence of more supply chain participants in the Old Trails region than in the representative region, since the Old Trails Region is close to Kansas City, MO, which is home to many agricultural processing and distribution companies. This explanation would be reinforced by the presence of amenity-driven experiences in the region such as the wineries.

\section{Example 3: New York State}

Schmit et al. (2016) report an economic impact multiplier of 1.87 for local food sales in the state of New Y ork. Using survey data collected from producers selling through local marketing channels in and around the state's capital, Albany, the authors generated a customized industry for small-scale, direct agriculture that is separate from conventional, commodity production. The authors then compared the total outlays across industries between those of small, direct agriculture; nonsmall, direct agriculture; and the default agricultural sector. They also generated and compared multipliers associated with each sector. They found that the small, direct agriculture sector had higher multipliers for employment and labor income, but smaller total value added and output values when compared to both the default and non-small, direct agriculture sectors. Several factors justify the relatively strong multiplier estimated by Schmit et al. Foremost is the recognition that New Y ork state is the fourth largest state in the United States, so that this large population supports a diverse and comprehensive economy, making it highly likely that inputs are available within the state. Furthermore, the state has a long and notable history of agricultural production and participation in the northeastern regional economy. It is also home to one of the largest and oldest farmers markets in the United States: G reenmarket, which has over 50 locations throughout New York City. Additionally, tradition and land development pressure have contributed to a more regionalized, smaller-scale, and diverse agricultural production system than what is utilized throughout much of the rest of the United States. Such an industry structure would suggest more input availability and higher labor utilization in New York than the average state. It is not surprising, then, that the LFIC estimated multiplier for this scenario is 1.72, less than that estimated by Schmit et al. (2016).

\section{Example 4: Midwest Self-Sufficiency in Fruits and Vegetables (A Multistate Region)}

Swenson (2011) analyzed the economic impact and distribution of a proposal to make a six-state region (Minnesota, Wisconsin, Illinois, Michigan, Indiana, and Iowa) self-sufficient in fruit and vegetables; that is, he examined the potential to grow sufficient amounts of fresh fruits and vegetables to meet the six states' consumer demand. Swenson found that US\$635 million of fruits and vegetables would need to be grown across the six states, and that gross impact would be US $\$ 1.03$ billion, implying a multiplier of 1.62. The LFIC estimates the impact multiplier to be higher, at 1.96. One possible reason for the difference in values is that Swenson's model explicitly accounts for countervailing effects such as land availability constraints and opportunity costs associated with producing alternative crops, whereas the LFIC simplistically assumes that land and labor are freely available for producing the additional quantities of fruits and vegetables.

\section{Discussion}

As illustrated by the literature review discussed above, and the description of the LFIC, conducting an economic impact analysis for local food systems requires extensive knowledge of the methodology as well as an extraordinary amount of data collection. This data collection is important in order to account for production differences within local food systems, accurately account for substitution effects, and subtract the opportunity costs of inputs. Such knowledge and data are beyond the reach of many local food system projects- either to do themselves or to afford someone to do it for them. The LFIC provides a second-best solution to enable stakeholders in the local food system to evaluate their project using a consistent methodology with reasonable assumptions. In this way, the calculator reflects a tradeoff of accuracy for a more accessible tool.

Users of the LFIC should reflect on how the impacts estimated might actually manifest in their communities. The literature cited earlier provides some key concepts that users should consider: 
- Of utmost importance is having a defensible estimate of total sales: the LFIC, like any calculator, will give an impact value for any number entered. If the value of total sales is not believable, however, the impact value is equally invalid. Be sure the sales numbers reflect actual transactions and can be documented. Beyond capturing actual sales, there are best practices in collecting primary data summarized in Thilmany McFadden et al. (2016), should the user need to gather data from vendors, suppliers, or others.

- To what extent are existing local food purchases being redirected to the local food project? The multiplier used in the LFIC does not explicitly net out the substitution effects of other local economic activity that is potentially displaced by the local food production. Consequently, this multiplier (and input-output analysis generally) is not meant to demonstrate the feasibility of a local food project. Instead, the impact value generated represents the gross value of the economic benefit a project has on the community's economy.

- What is the best alternative use of the land and labor involved with the local food system? If the inputs were previously idle or underutilized, then no adjustment is likely necessary to capture lost productivity from these inputs. However, if the inputs were fully utilized, then some consideration of the value of the productivity lost should offset the value of production from the local food project, thereby reducing the multiplier.

It is important to note that there are other economic and nonfinancial benefits that occur when local food systems are expanded. For example, there may be positive externalities or public goods that occur with the introduction or expansion of local food systems (Winfree $\&$ Watson, 2017). This would occur when components of local food systems facilitate well-being in the community through stronger social capital, increased innovation, and the creation of amenities attractive to high-skilled and creative people. Additionally, O 'Hara and Shideler (2018) found evidence that, in metropolitan counties, increasing direct-toconsumer food sales increased sales at restaurants, but not at grocery and specialty food stores. This correlation suggests that there may be an economic-development rationale for local food systems, although research that includes a broader geographic region is warranted. Neither of these types of impacts is reflected in the LFIC. However, it must also be noted that, in addition to potential benefits, there are potential costs associated with promoting local food systems. One such cost includes the potential for a loss of efficiency in our food production system and a "beggar thy neighbor" mentality where benefits and costs to people outside the sphere of "local" are discounted (Lusk \& Norwood, 2011).

\section{Conclusion}

The objectives of this paper are twofold: to provide local food system practitioners with an awareness of how economic impact analysis is conducted, and to introduce the Local Food Impact Calculator, a tool that can assist local food system practitioners in estimating the economic impact of their project. Local food multipliers, the common output of economic impact analysis, represent one avenue for understanding how local food systems interact with a local economy. Because of the complexity and expense associated with performing these analyses, the Local Food Impact Calculator is presented as an accessible and methodologically sound tool for use by this audience.

As with any economic impact analysis, the objective should be to understand which other sectors in the local economy are impacted by local food operations. While multipliers are a common output from these studies, and while they may also appear to be precise, food system practitioners should recognize that they are approximations and reflect many assumptions associated with the data and methodology. Thus, they should be interpreted and applied in a prudent fashion. When used carefully, the LFIC provides users with a credible tool to communicate how local foods can contribute to local economic development efforts. Such communication could justify local government investments 
Journal of Agriculture, Food Systems, and Community Development

ISSN: 2152-0801 online

https:/ / www.foodsystemsjournal.org

in infrastructure to support local foods, like a

building a permanent farmers market pavilion or

connecting an existing facility to utilities so it can support cold storage, accept supplemental nutrition benefits payments, and/ or host cooking demonstrations.

\section{References}

Angelo, B. E., Jablonski, B. B. R., \& Thilmany, D . (2016). Meta-analysis of US intermediated food markets: Measuring what matters. British F ood Journal, 118(5), 1146-1162. https:/ / doi.org/ 10.1108/ BFJ-10-2015-0403

Brown, A. (2002). Farmers' market research 1940-2000: An inventory and review. A merican Journal of A lternative A griculture, 17(4), 167-176. Retrieved from https:/ / www.cambridge.org/ core/ journals/ american-journal-ofalternative-agriculture/

Brown, C., \& Miller, S. (2008). The impacts of local markets: A review of research on farmers markets and community supported agriculture (CSA). A merican Journal of A gricultural E conomics, 90(5), 1298-1302.

https:/ / doi.org/ 10.1111/ j.1467-8276.2008.01220.x

Carpio, C. E., \& Isengildina-Massa, O . (2010). To fund or not to fund: Assessment of the potential impact of a regional promotion campaign. Journal of A griaultural and Resource E conomics, 35(2), 245-260.

Conner, D. S., Knudson, W. A., Hamm, M. W., \& Peterson, H. C. (2008). The food system as an economic driver: Strategies and applications for Michigan. Journal of $\mathrm{H}$ unger and E nvironmental N utrition, 3(4), 371-383. https:// doi.org/ 10.1080/ 19320240802528849

Darby, K., Batte, M. T., Emst, S., \& Roe, B. (2008). D ecomposing local: A conjoint analysis of locally produced foods. A merican Journal of A gricultural E conomics, 90(2), 476-486. https:/ / doi.org/ 10.1111/ j.1467-8276.2007.01111.x

Day-Farnsworth, L., McCown, B., Miller, M., \& Pfeiffer, A. (2009). Scaling up: M eeting the demand for local food. Madison: University of Wisconsin Extension Ag Innovation Center \& UW Madison Center for Integrated Agricultural Systems. Retrieved from http:// www.cias.wisc.edu/ wp-content/ uploads/ 2010/ 01/ baldwin web final.pdf

Diamond, A., \& Barham, J. (2011). Money and mission: Moving food with value and values. Journal of A griaultural, F ood Systems, and Community D evelopment, 1(4), 101-117. http:/ / dx.doi.org/ 10.5304/ jafscd.2011.014.013

Gunter, A., \& Thilmany, D . (2012). Economic implications of farm to school for a rural Colorado Community. Rural Connections, 6(2), 13-16.

Henneberry, S. R., Whitacre, B. E., \& Agustini, H. N. (2009). An evaluation of the economic impacts of Oklahoma farmers markets. Journal of F ood D istribution Research, 40(3), 64-78.

$\mathrm{Hu}, \mathrm{W}$. (2012). E valuating structural and performance dynamics of a differentiated U.S. apple industry (D octoral dissertation). Colorado State University, Fort Collins, Colorado.

Hughes, D. W., Brown, C., Miller, S., \& McConnell, T. (2008). Evaluating the economic impact of farmers' markets using an opportunity cost framework. Journal of A gricultural and A pplied E conomics, 40(1), 253-265. https:/ / doi.org/ 10.1017/ S1074070800028091

Lev, L., Brewer, L., \& Stephenson, G . (2003). Research brief: H ow do farmers mark ets affect neighboring businesses? (O regon Small Farms Technical Report No. 16). Corvallis : O regon State University Extension Service.

Lusk, J. L., \& Norwood, F. B. (2011). The locavore's dilemma: Why pineapples shouldn't be grown in North D akota. The L ibrary of E conomics and L iberty. Retrieved from https:// www.econlib.org/ library/ Columns/y2011/ LuskNorwoodlocavore.html

Martinez, S., Hand, M., D a Pra, M., Pollack, S., Ralston, K., Smith, T., ... Newman, C. (2010). L ocal food systems: Concepts, impads and issues (Economic Research Report 97). Washington, D.C.: U.S. D epartment of Agriculture, Economic Research Service.

Matson, J., Sullins, M., \& Cook, C. (2013). The role of food hubs in local food mark eting (Service Report 73). Washington, DC: U.S. D epartment of Agriculture, Rural D evelopment.

Miller, S. R., Mann, J., Barry, J., Kalchik, T., Pirog, R., \& Hamm, M. W. (2015). A replicable model for valuing local food systems. Journal of A griaultural and A pplied E conomics, 47(4), 441-461. http:/ / dx.doi.org/ 10.1017/ aae.2015.19

Myers, G. S. (2006). H oward County farmers' mark et economic impact study 2004. Howard County Economic D evelopment Authority, Agricultural Marketing Program, Maryland. 
O 'Hara, J. K., \& Shideler, D . (2018). D o farmers' markets boost Main Street? D irect-to-consumer agricultural production impacts on the food retail sector. Journal of F ood D istribution Research, 49(2), 19-37. Retrieved from https:/ / www.fdrsinc.org/ wp-content/ uploads/ 2018/ 07/ JFDR 49.2.pdf\#page=23

O berholtzer, L., \& G row, S. (2003). Produœer-only farmers' mark ets in the Mid-A tlantic region: A survey of mark et managers. Arlington, Virginia: Wallace Center at Winrock International.

Onozaka, Y., \& Thilmany McFadden, D. (2011). D oes local labeling complement or compete with other sustainable labels? A conjoint analysis of direct and joint values for fresh produce claim. A merican Journal of A gricultural $\mathrm{E}$ conomics, 93(3), 693- 706. https:/ / doi.org/ 10.1093/ ajae/ aar005

Otto, D ., \& Varner, T. (2005). C onsumers, vendors, and the economic importance of Iowa farmers' mark ets: A n economic impact survey analysis. Ames, Iowa: Leopold Center for Sustainable Agriculture. Retrieved from http:/ / lib.dr.iastate.edu/ leopold pubspapers/ 145

Rossi, J. D ., Johnson, T. G ., \& Hendrickson, M. (2017). The economic impacts of local and conventional food sales. Journal of A griaultural and A pplied E conomics, 49(4), 555-570. https:// doi.org/ 10.1017/ aae.2017.14

Schmit, T. M., \& Jablonski, B. B. R. (2017) A practitioner's guide to conducting an economic impact assessment of regional food hubs using IMPLAN: A systematic approach. In E B 2017-01, Charles H. Dyson School of Applied Economics and Management (pp. 1-53). Ithaca, New Y ork: Cornell Univeristy, College of Agriculture and Life Sciences. Retrieved from https:/ / www.ams.usda.gov/ sites/ default/ files/ media/ EB2017APractitionersG uide.pdf

Schmit, T. M., Jablonski, B. B. R., \& Mansury, Y. (2016). Assessing the economic impacts of local food system producers by scale: A case study from New York. E conomic D evelopment Q uarterly, 30(4), 316-328. https:/ / doi.org/ 10.1177/ 0891242416657156

Stevenson, G. W., Clancy, K., King, R., Lev, L., O strom, M., \& Smith, S. (2011). Midscale food value chains: An introduction. Journal of A grialtural, F ood Systems, and C ommunity D evelopment, 1(4), 27-34. https:/ / doi.org/ 10.5304/ jafscd.2011.014.007

Stickel, M., \& D eller, S. (2014). C ommunity-level impacts of local food movements in the U.S., Canada and W estern E urope: A nnotated bibliography (Staff Paper Series 576). Madison: D epartment of Agricultural and Applied Economics, University of Wisconsin.

Swenson, D . (2006). Buying local in Marshall C ounty and M arshalltown, Iowa: A n economic impact assessment. Ames: Iowa State University. Retrieved from http:/ / www2.econ.iastate.edu/ papers/ paper 12590.pdf

Swenson, D . (2010) Selected measures of the economic values of increased fruit and vegetable production and consumption in the upper mM idwest. Retrieved from Ames, IA: Leopold Center for Sustainable Agriculture, Iowa State University.

Swenson, D . (2011). M easuring the economic impads of increased fresh fruit and vegetable production in Iowa considering metropolitan demand. Retrieved from Ames, IA: Leopold Center for Sustainable Agriculture, Iowa State University.

Swenson, D . (2013). The economic contribution potential of local foods production in Kane C ounty, Illinois (Economics Technical Reports and White Papers 3). Ames: Iowa State University. Retrieved from https:/ / lib.dr.iastate.edu/ econ reportspapers/3/

Thilmany, D., Watson, P., \& Kress, G. (2006). The economic contribution of Colorado's wine industry. Fort Collins, Colorado: Department of Agricultural and Resource Economics. Retrieved from https:/ / webdoc.agsci.colostate.edu/ DARE/ EDR/ ED R06-08.pdf

Thilmany McFadden, D ., Conner, D ., D eller, S., Hughes, D ., Meter, K., Morales, A., ... Tropp, D . (2016). The economics of local food systems: A toolkit to guide community discussions, assessments, and choios. U.S. D epartment of Agriculture, Agricultural Marketing Service. Retrieved from https:// www.ams.usda.gov/ sites/ default/ files/ media/ EconomicsofLocalFoodSystemsToolkit.pdf

Thilmany McFadden, D ., \& Low, S. A. (2012). Will local foods influence American diets? C hoiœs, 27(1).

U.S. D epartment of Agriculture, National Agricultural Statistics Service (2009). 2007 C ensus of A griculture. Retrieved from https:/ / quickstats.nass.usda.gov/

U.S. D epartment of Agriculture, National Agricultural Statistics Service. (2014). 2012 C ensus of A griculture. Retrieved from https:/ / quickstats.nass.usda.gov/ 
Journal of Agriculture, Food Systems, and Community Development ISSN: 2152-0801 online

https:/ / www.foodsystemsjournal.org

Watson, P., Cooke, S., Kay, D., Alward, G., \& Morales, A. (2017). A method for evaluating the economic contribution of a local food system. Journal of A gricultural and Resource E conomics, 42(2), 180-194. Retrieved from http:/ / www.waeaonline.org/ UserFiles/ file/ JARE42.2May20174Watson180-194.pdf

Winfree, J., \& Watson, P. (2017). The welfare economics of "buy local." A merican Journal of A gricultural E onomics, 99(4), 971-987. https:/ / doi.org/ 10.1093/ ajae/ aaw104 